\title{
Primary and secondary organic aerosol origin by combined gas-particle phase source apportionment
}

Crippa Monica ${ }^{1}$, Canonaco Francesco ${ }^{1}$, Slowik Jay G. ${ }^{1}$, El Haddad Imad ${ }^{1}$, DeCarlo Peter F. ${ }^{1^{\star}}$, Mohr Claudia ${ }^{1^{\star \star}}$, Heringa Maarten F. ${ }^{1^{\star \star \star}}$, Chirico Roberto $^{1^{\star \star \star \star}}$, Marchand Nicolas ${ }^{2}$, Temime-Roussel Brice ${ }^{2}$, Abidi Ehgere ${ }^{2}$, Poulain Laurent ${ }^{3}$, Wiedensohler Alfred ${ }^{3}$, Baltensperger Urs ${ }^{1}$, Prévôt Andre S. H. $^{1}$

[1]\{Laboratory of Atmospheric Chemistry, Paul Scherrer Institute, PSI Villigen, 5232, Switzerland $\}$

[2]\{Aix-Marseille Université, CNRS, LCE FRE 3416, 13331, Marseille, France\} [3]\{Leibniz Institute for Tropospheric Research, Permoserstr 15, 04318, Leipzig, Germany\}

[*] nnow at: Department of Civil, Architectural, and Environmental Engineering and Department of Chemistry, Drexel University, Philadelphia, PA, USA, 19104\}

[**] \{now at: Department of Atmospheric Sciences, University of Washington, Seattle WA 98195, USA

[***]\{now at: WIL Research, 5203 DL 's-Hertogenbosch, The Netherlands

$[* * * *]$ now at: Italian National Agency for New Technologies, Energy and Sustainable Economic Development (ENEA), UTAPRAD-DIM, Via E. Fermi 45, 00044 Frascati, Italy

Correspondence to: A.S.H. Prévôt (andre.prevot@psi.ch) 
SI-1 Comparison of PMF AMS $_{\text {and }}$ PMF AMS-PTRMS $_{\text {results }}$

Here the comparison of the time series retrieved for two separate source apportionment approaches is presented: positive matrix factorization (PMF) applied to AMS data only $\left(\mathrm{PMF}_{\mathrm{AMS}}\right)$ and PMF applied to the combined AMS-PTRMS dataset (PMF $\left.\mathrm{PMS}_{\text {AMTRMS }}\right)$. For the winter campaign, details about the AMS only source apportionment can be found in Crippa et al. (2013a), while for the summer campaign the reference papers are Freutel et al. (2013) and Crippa et al. (2013b).

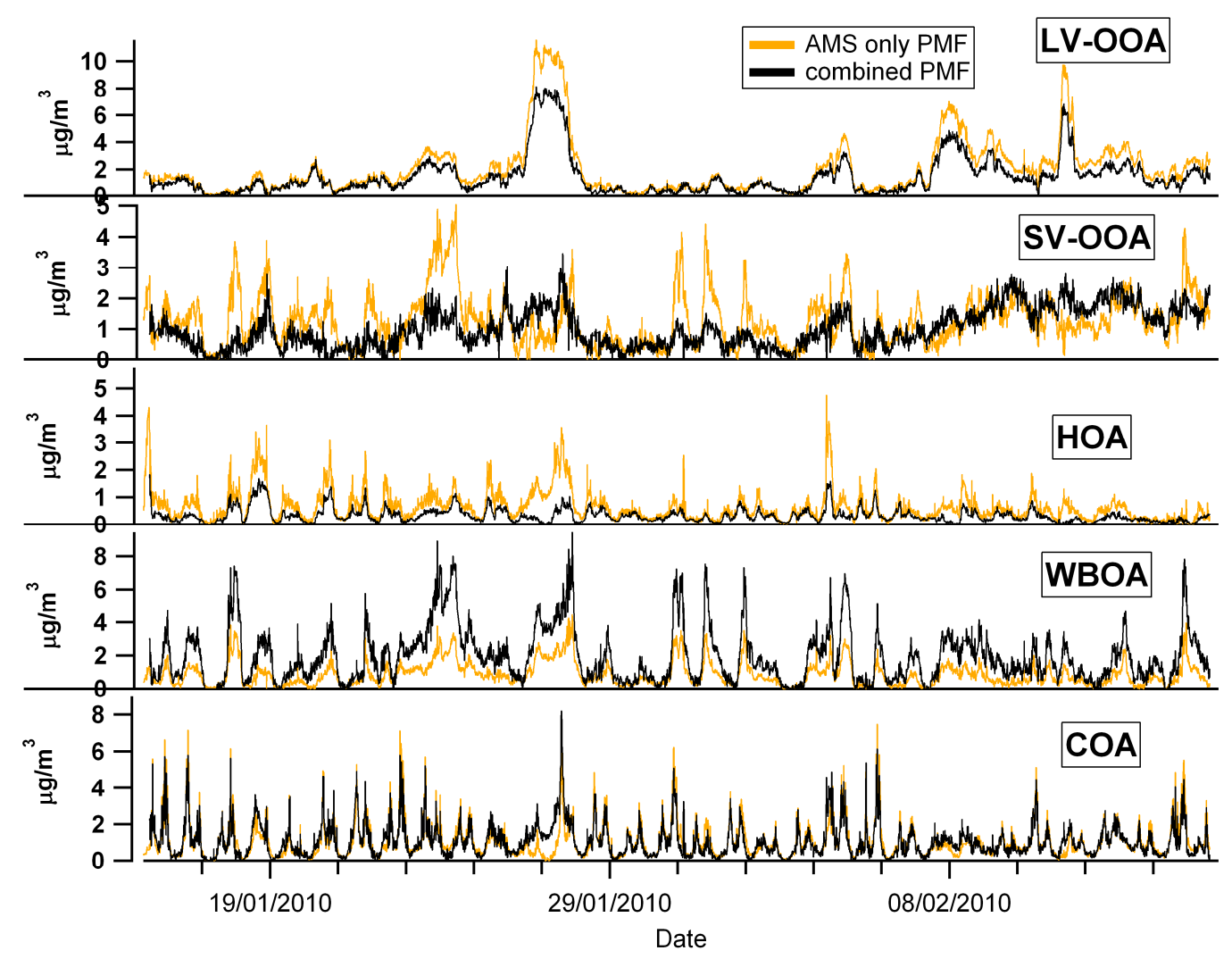

Figure SI-1.1: Time series comparison of AMS sources obtained with the PMF and the combined $\mathbf{P M F}_{\mathrm{AMS}-\mathrm{P} T R M S}$ for the winter campaign. Note that the semi-

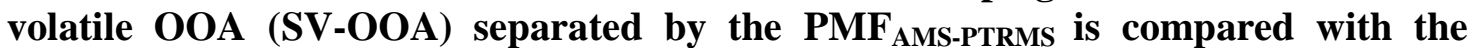
$\mathrm{OOA}_{2}$-BBOA factors obtained with the $\mathrm{PMF}_{\mathrm{AMS}}$. 


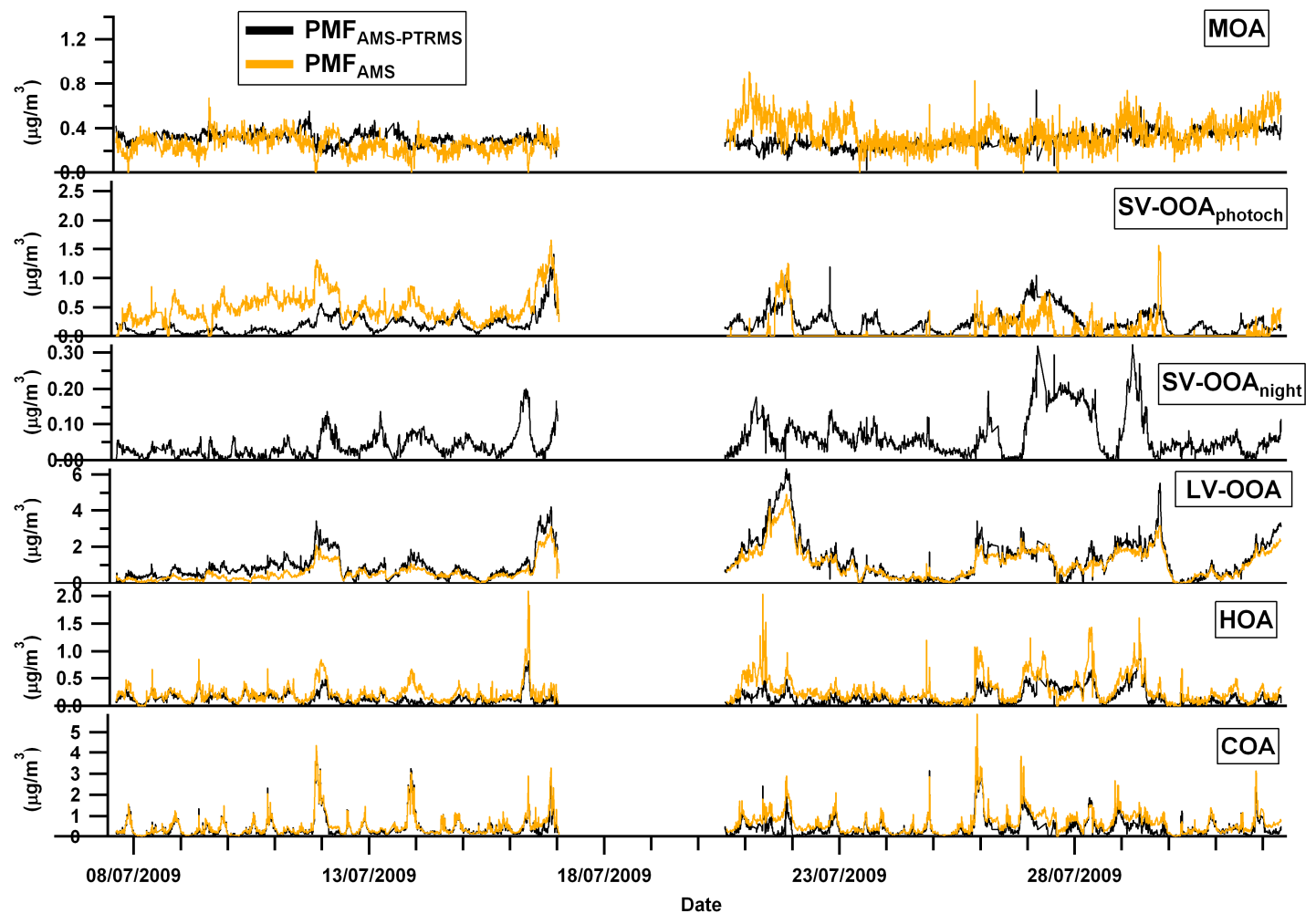

Figure SI-1.2: Time series comparison of AMS sources obtained for the LHVP site with the $\mathrm{PMF}_{\mathrm{AMS}}$ and the combined $\mathrm{PMF}_{\mathrm{AMS} \text {-PTRMS }}$ for the summer campaign. 


\section{SI-2 Diurnals of OA components obtained with the $\mathbf{P M F}_{\text {AMS-PTRMS }}$}

Figures SI-2.1 and SI-2.2 show the diurnal patterns of gas and particle phase components retrieved by the $\mathrm{PMF}_{\mathrm{AMS} \text {-PTRMS }}$ for the summer and winter campaigns. Although the temporal variation of the PTR-MS and AMS sources is the same within each season, some patterns are highlighted by the different contribution of a specific source to the gas or particle phase. For example, the semi-volatile behavior of the nighttime OOA component separated during the summer campaign shows much higher contribution for the PTR-MS data than for the AMS one and a clearer diurnal pattern as well.
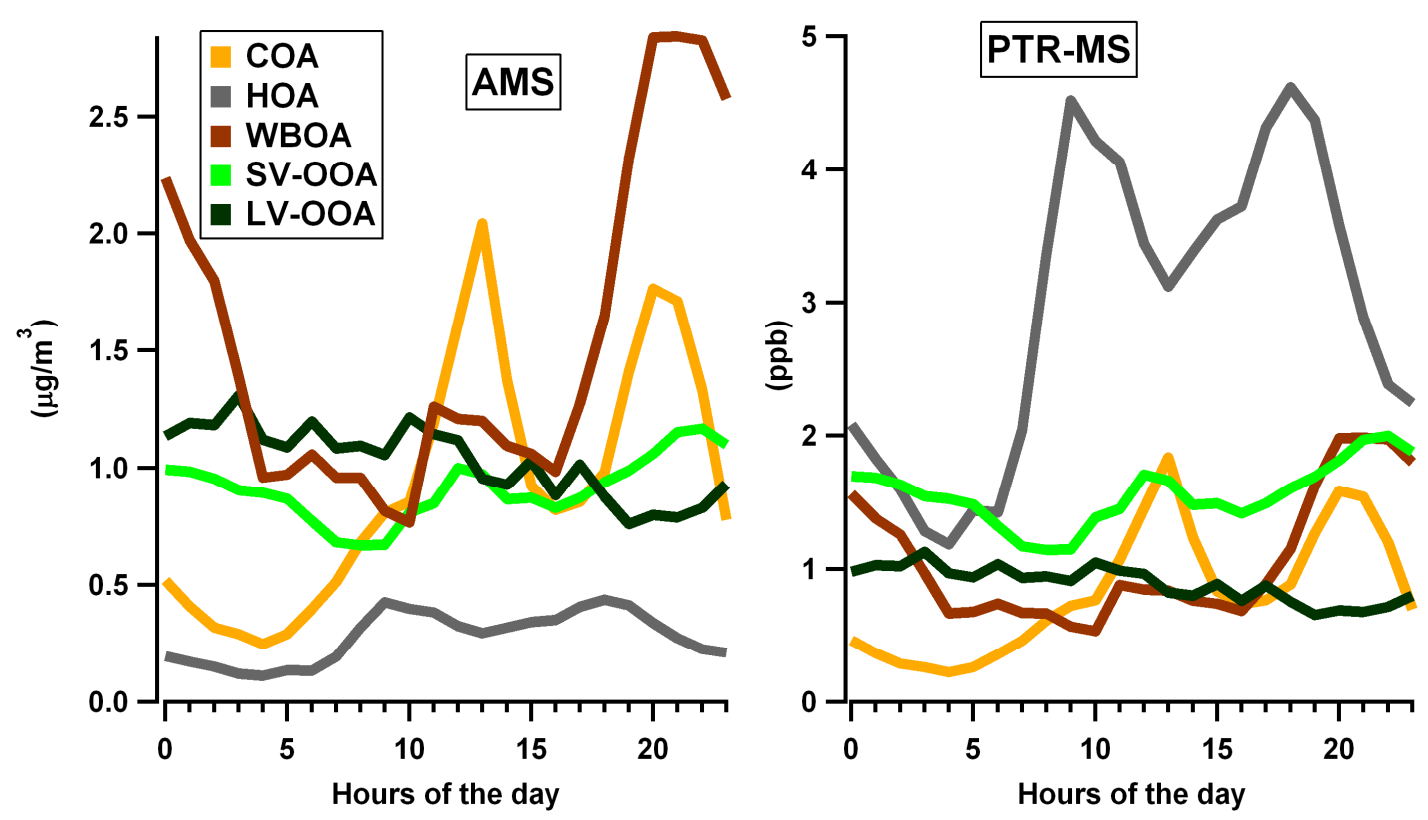

Figure SI-2.1: Diurnal variations of the PMF factors for the AMS and PTR-MS measurements retrieved from the PMF ${ }_{\text {AMS-PTRMs }}$ approach. Median values are represented (winter campaign). 

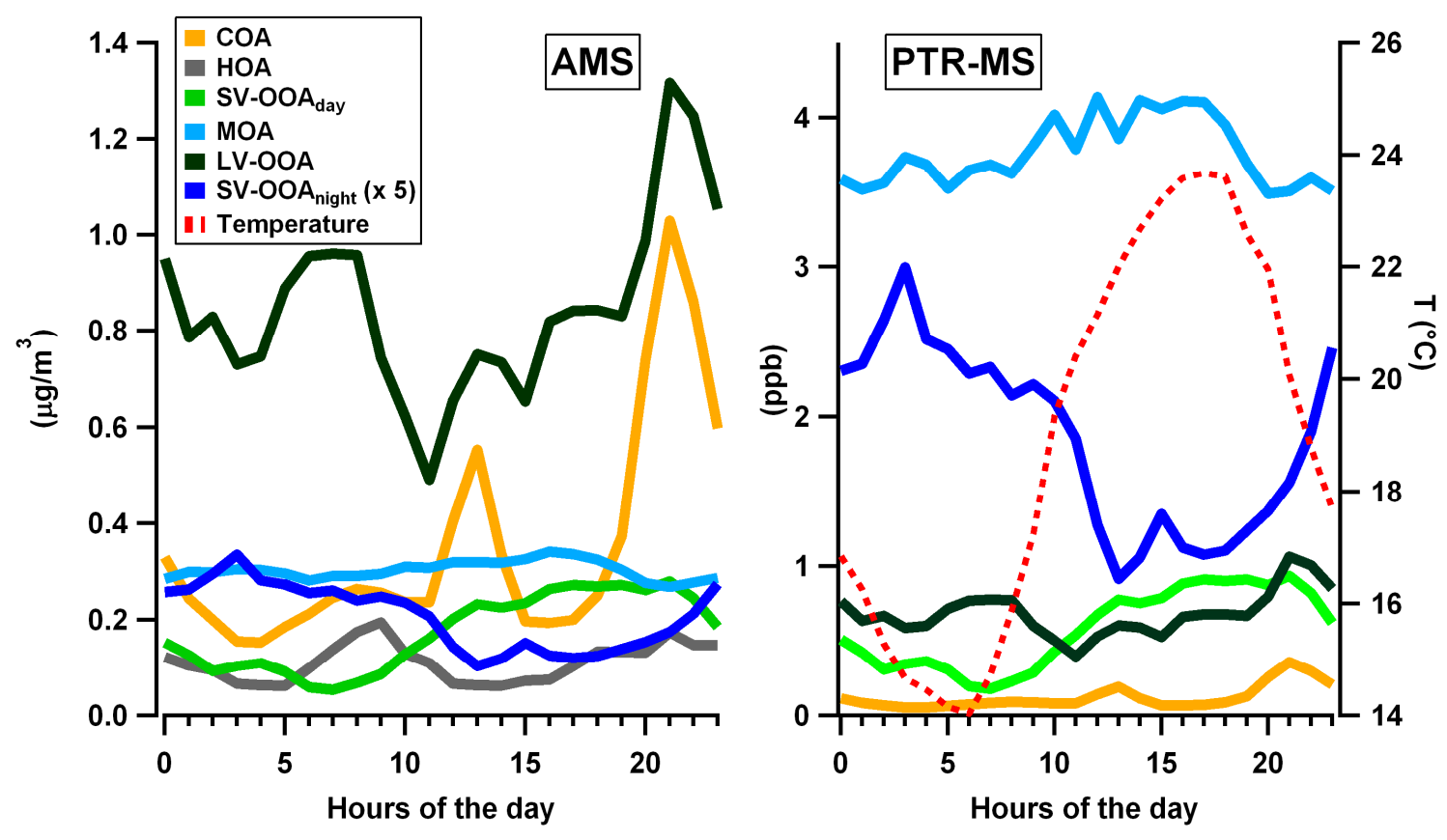

Figure SI-2.2: Diurnal variations of the PMF factors for the AMS and PTR-MS measurements retrieved from the $\mathbf{P M F}_{\text {AMS-PTRMs }}$ approach. Median values are represented (summer campaign). 
SI-3 Seasonal comparison of PTR-MS sources mass spectra obtained from the PMF $_{\text {AMS-PTRMS }}$

Here the PTR-MS mass spectra obtained from the combined gas-particle phase source apportionment are compared for the two campaigns. Note that only common sources for the two seasons are reported (e.g. biomass burning is not shown since it only contributed during wintertime). The PTR-MS mass spectra for traffic and LV-OOA are quite stable for the two seasons, while some differences are observed for the cooking and SV-OOA nighttime factors.

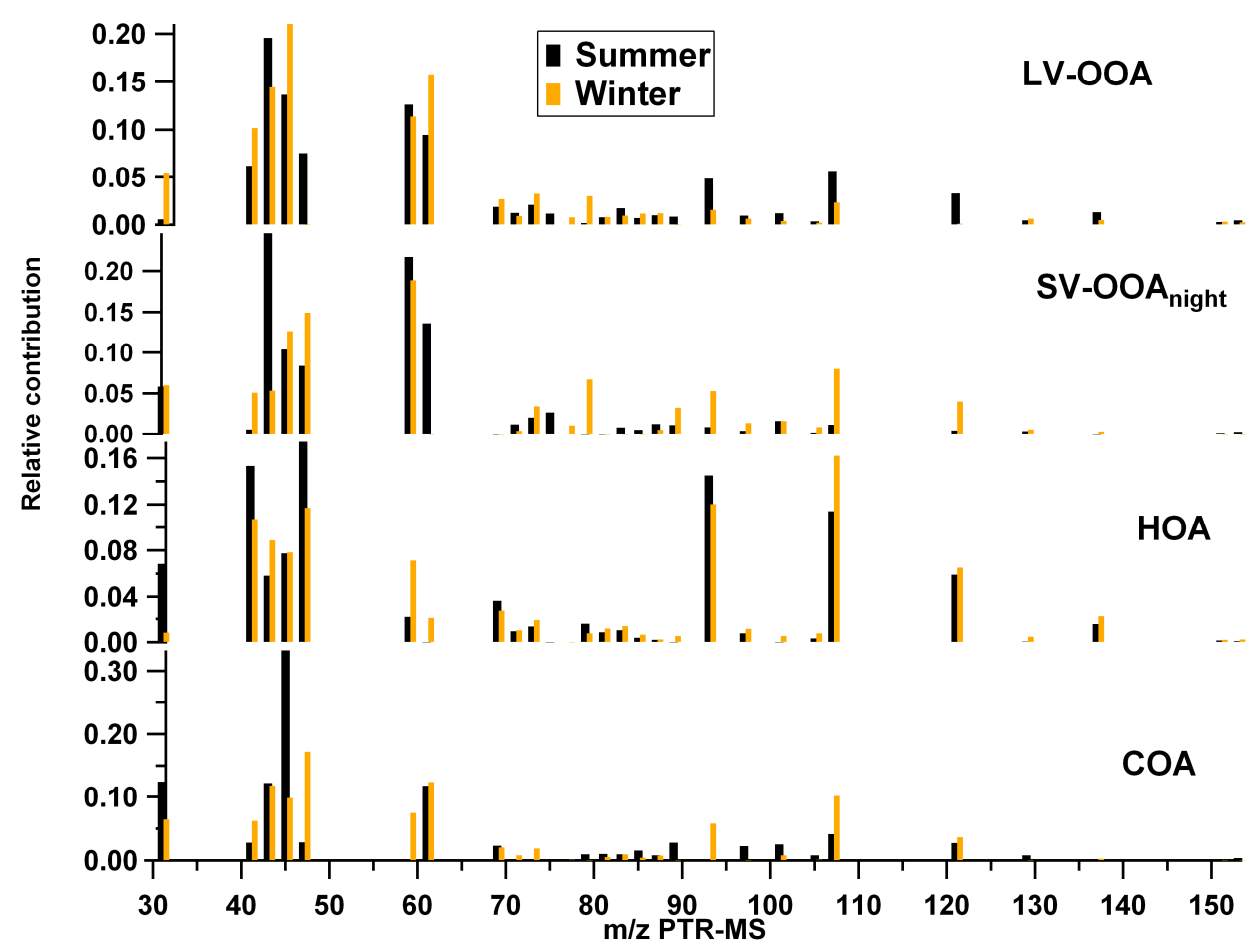

Figure SI-3.1: Comparison of PTR-MS source spectra obtained for the summer and winter campaigns. Each mass spectrum is normalized to 1. 


\section{SI-4 PMF diagnostics}

\section{SI-4.1 Residuals}

In this section the residuals $\left(\mathrm{Q} / \mathrm{Q}_{\mathrm{exp}}\right)$ for the chosen solutions $\left(7\right.$ factors, $\mathrm{C}_{\mathrm{PTR}}=0.8$ and 6 factors, $\mathrm{C}_{\mathrm{PTR}}=0.7$ for winter) of the combined $\mathrm{PMF}$ approach are reported for both seasons (Fig.SI-4.1 and SI-4.2). Note that the step in the residual time series plot observed for the summer campaign (Fig.SI-4.2) is a consequence of a power failure and instrumental issues (e.g. tuning, etc.) happened in the middle of the campaign.
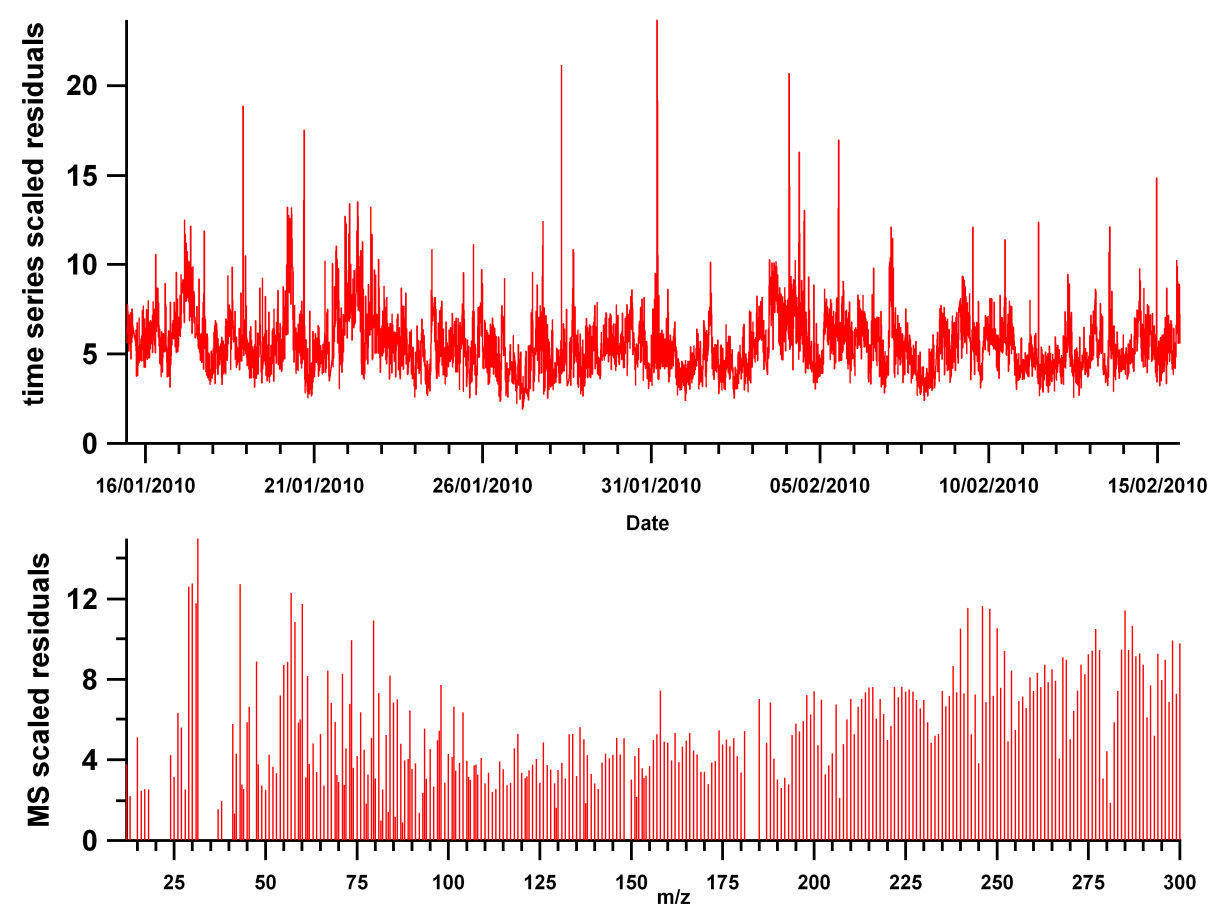

Figure SI-4.1.1: Scaled residuals in terms of mass spectra and time series of the PMF $_{\text {AMS-PTRMS }}$ case for the winter campaign. 

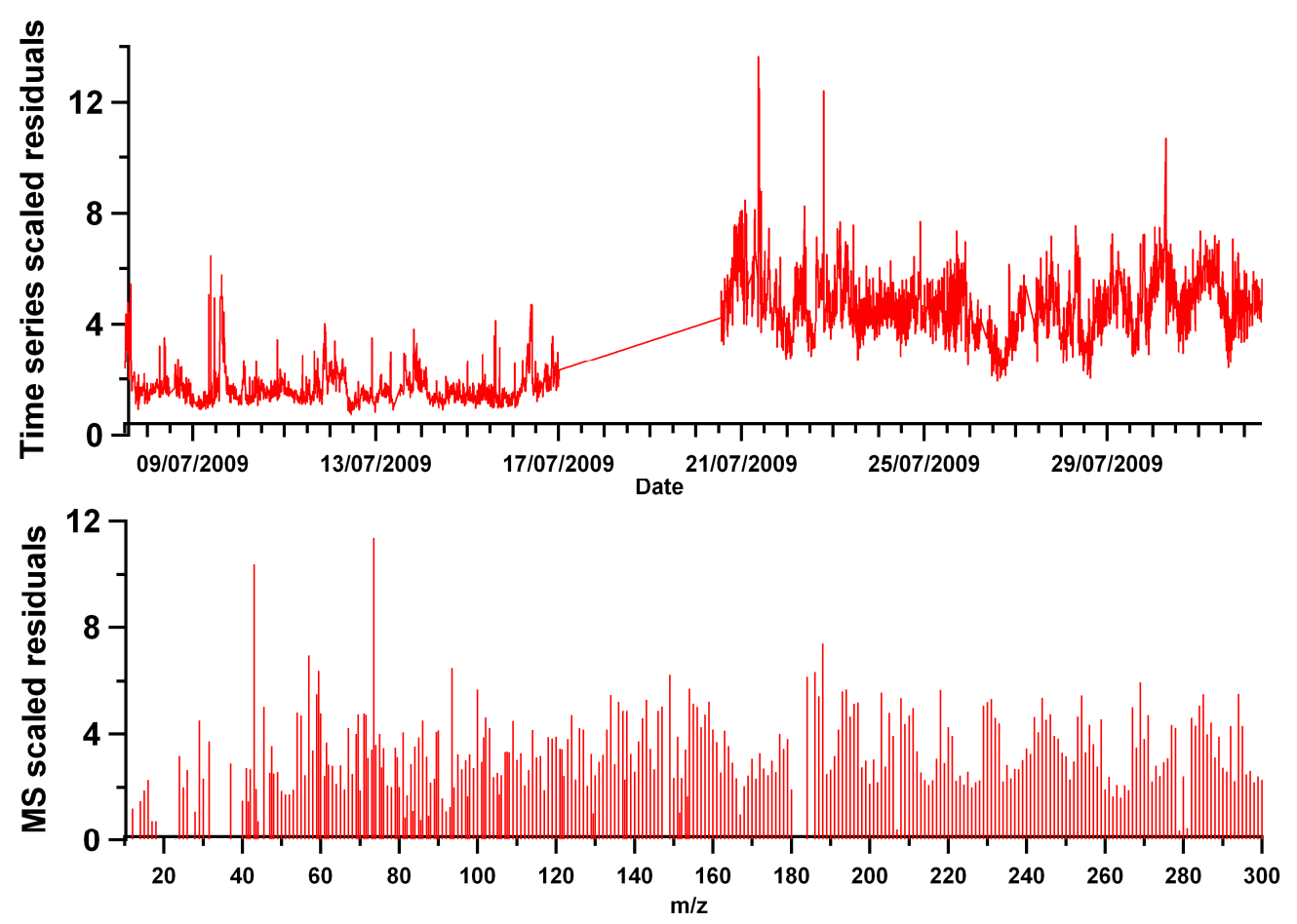

Figure SI-4.1.2: Scaled residuals in terms of mass spectra and time series of the PMF $_{\text {AMS-PTRMS }}$ case for the summer campaign. 


\section{SI-4.2 Stability of the solution}

In this paper the 7 factors solution with $C_{P T R}=0.8$ for the summer campaign and the 6 factors solution with $C_{P T R}=0.7$ for the winter case were presented. The choice of these solutions was based on several concurrent criteria (see also section 3 of the manuscript).

First of all, $\overline{\Delta E}$ was used to define a region $(0 \pm 0.25)$ where both instruments were well represented in the PMF solution. Then, all solutions lying within the selected region were investigated and evaluated based on the physical interpretability of the factors (e.g. given by time series correlations with independent measurements, MS correlation with literature studies, diurnal pattern investigation, analysis of the residuals, PTR-MS tracers coherence, etc.). From these investigations, an optimal solution was adopted.

In contrast to PMF applied to the dataset of a single instrument, here multiple solutions can be obtained not only changing the number of factors but also varying the weighting parameter $C_{P T R}$. This makes the analysis quite complex and it is often difficult to be able to compare within a fixed number of factors how the solution changes varying the $C_{P T R}$ value, because it often implies significant changes in $\mathrm{Q} / \mathrm{Q}_{\exp }$ calculated using the original unweighted errors (in some cases more than $20 \%$ when applying an increasing step of 0.1 in the $C_{P T R}$ value).

For this reason the stability of the chosen solution was assessed using the fpeak parameter, in order to evaluate the effect of mathematical rotations on the solution, and initializing the algorithm with 30 different starting points (seeds). Results of these analyses are reported below. Note that when representing the relative factors contribution versus fpeak or seed values the sum of AMS and PTR-MS data was considered.

Figures SI-4.2.1 and SI-4.2.2 represent the relative contribution of each identified factor during the winter campaign versus the fpeak parameter or the seed value. The $Q / Q_{\exp }$ plot is also reported as diagnostic. In order to evaluate how much stable is the solution, the fpeak parameter was varied between -2 and +2 corresponding to a relative change in the $\mathrm{Q} / \mathrm{Q}_{\exp }$ graph maximum of $40 \%$. However the solution appears to be rather constant over the investigated fpeak range. Moreover, the presence of local minima was analyzed initializing the algorithm with 30 different points, corresponding again to a relative change in the $\mathrm{Q} / \mathrm{Q}_{\text {exp }}$ plot of maximum $40 \%$. Also in this case the solution appears to be stable in terms of source attribution. 

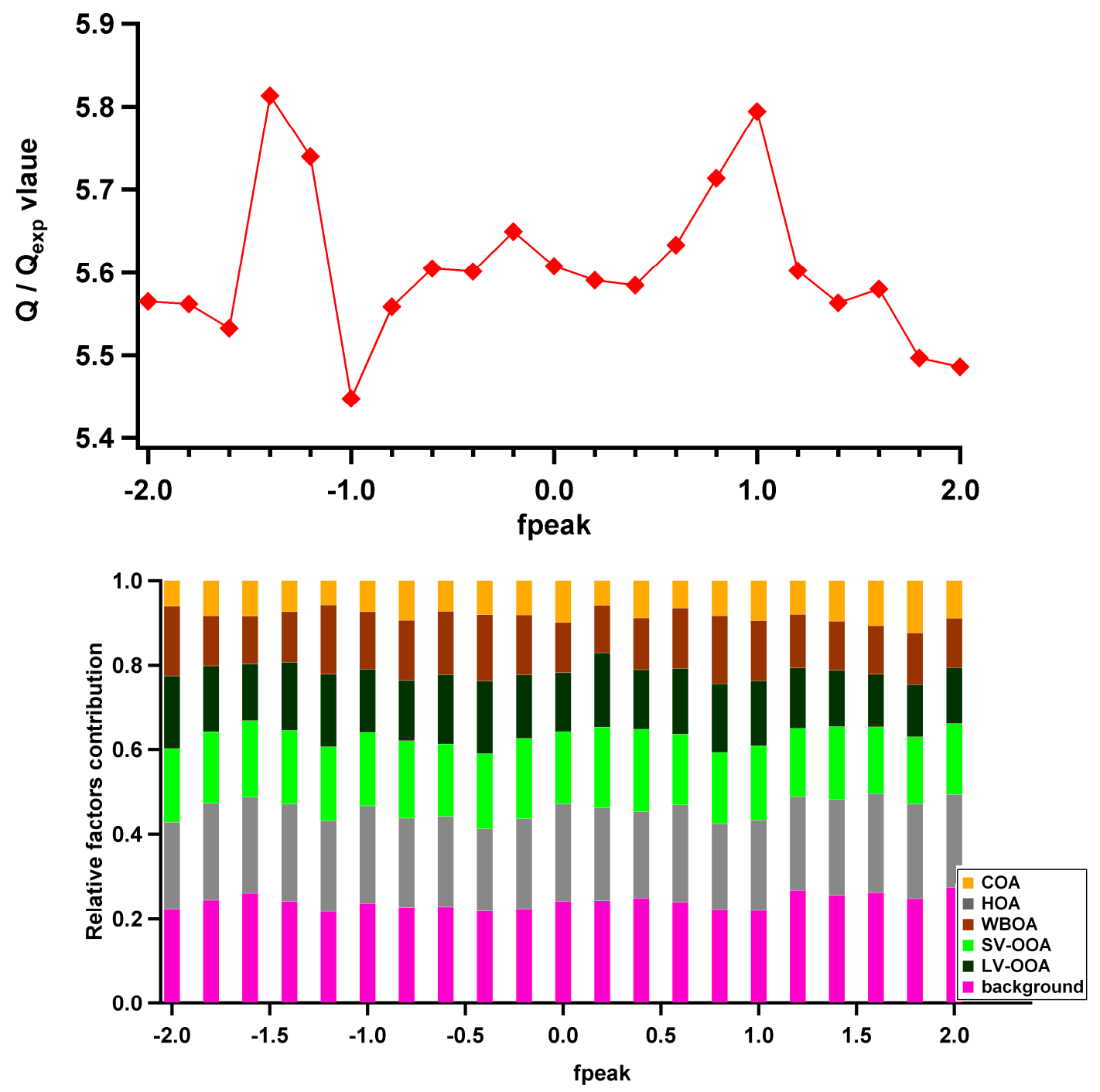

Figure SI-4.2.1: Variability of the relative factor contributions and the corresponding $Q / Q_{\exp }$ values with the fpeak parameter during the winter campaign. 

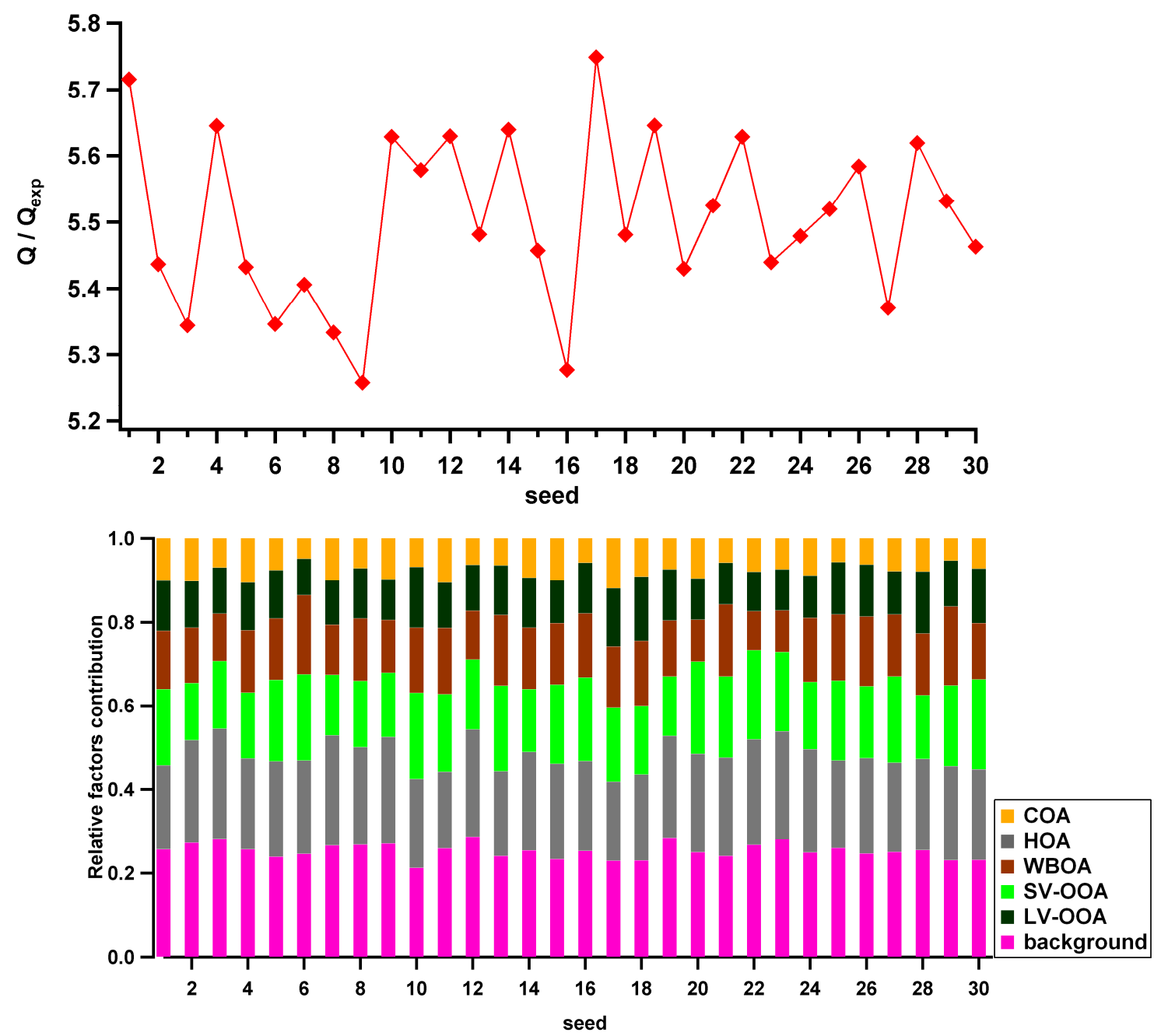

Figure SI-4.2.2: Variability of the relative factor contributions and the corresponding $Q / Q_{\exp }$ values with 30 different initial values (seeds) during the winter campaign. 
Figures SI-4.2.3 and SI-4.2.4 show similar plots to the two previously described. The summer solution seem to be partially affected by the additional rotations explored with the fpeak parameter (e.g. at fpeak=0.8). Finally, the chosen solution did not represent a local minimum as confirmed by Figure SI-4.2.4.
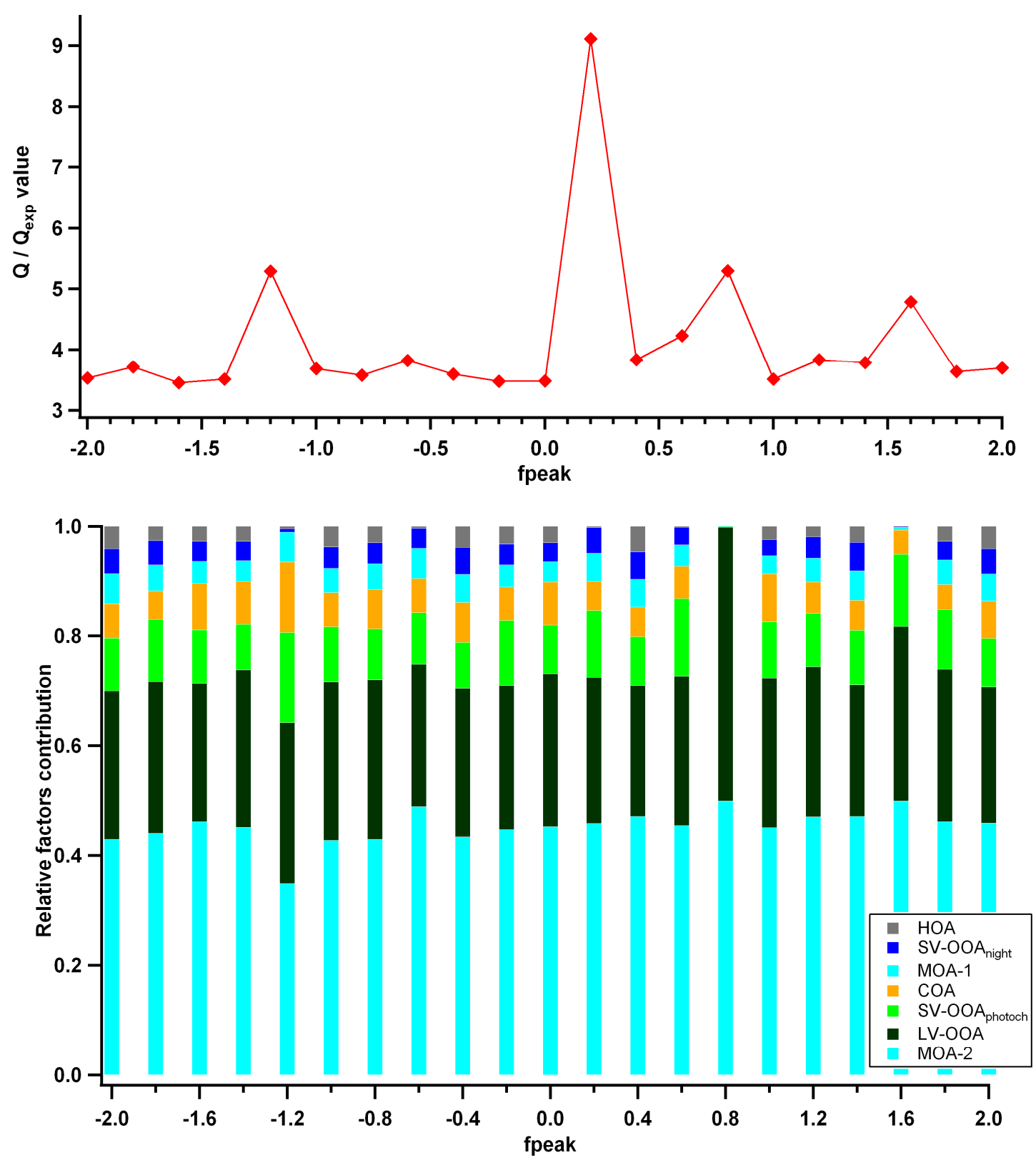

Figure SI-4.2.3: Variability of the relative factor contributions and the corresponding $Q / Q_{\exp }$ values with the fpeak parameter during the summer campaign. 

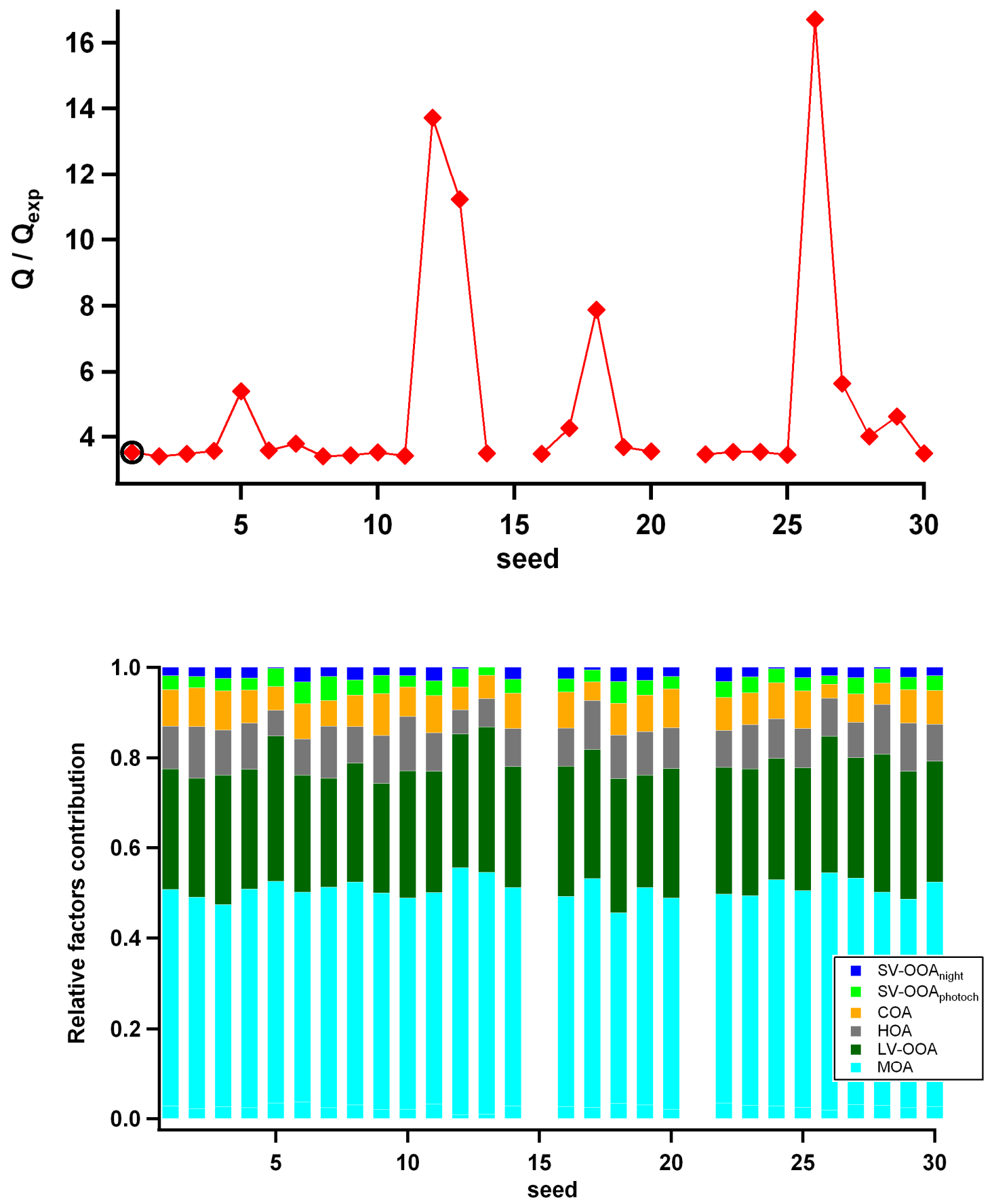

Figure SI-4.2.4: Variability of the relative factor contributions and the corresponding $Q / Q_{\exp }$ values with 30 different initial values (seeds) during the summer campaign. 


\section{SI-5 Winter campaign PTR-MS background factor}

The PMF $\mathrm{AMS}_{\text {AMTRMS }}$ applied to the winter dataset allowed the separation of a factor which represents instrumental issues related with the PTR-MS measurements. Figure SI-5.1 represents the time series of this factor contributing to the PTR-MS measurements and its mass spectrum both for the AMS and PTR-MS. This factor represents on average $32 \%$ of the total gas phase measurements, while its contribution is negligible for the AMS fraction (on average only $2 \%$ of the total AMS organic mass). Its time series shows a continuous decrease, which likely represents an outgassing in the Teflon sampling line. While several masses contribute to the PTR-MS mass spectrum, Table 1 indicates $m / z, 47$, $89,97,101$ and 105 as the ones that are most unique to this factor. We preferred not to exclude these masses from the PTR-MS dataset because this instrumental problem does not only affect these prominent peaks but to a lesser extent all the PTR-MS masses and therefore is impossible to correct for consistently without introducing additional bias.

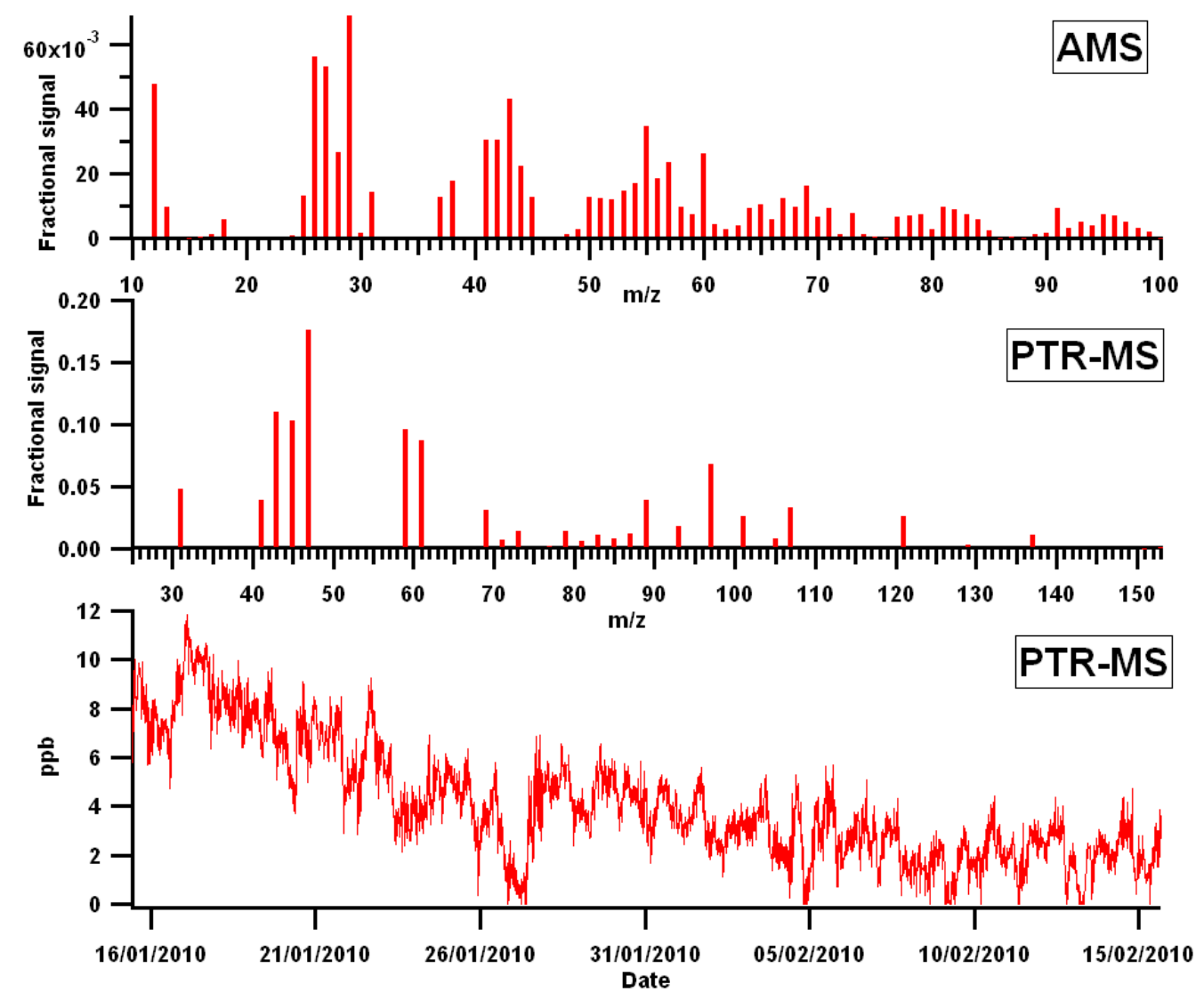

Figure SI-5.1: Time series and mass spectrum of the background factor separated for the PMF $_{\text {AMS-PTRMs }}$ during the winter campaign. 


\section{References}

Crippa, M., DeCarlo, P. F., Slowik, J. G., Mohr, C., Heringa, M. F., Chirico, R., Poulain, L., Freutel, F., Sciare, J., Cozic, J., Di Marco, C. F., Elsasser, M., José, N., Marchand, N., Abidi, E., Wiedensohler, A., Drewnick, F., Schneider, J., Borrmann, S., Nemitz, E., Zimmermann, R., Jaffrezo, J.-L., Prévôt, A. S. H., and Baltensperger, U.: Wintertime aerosol chemical composition and source apportionment of the organic fraction in the metropolitan area of Paris, Atmos. Chem. Phys., 13, 961-981, 2013a.

Crippa, M., El Haddad, I., Slowik, J. G., DeCarlo, P. F., Mohr, C., Heringa, M., Chirico, R., Marchand, N., Sciare, J., Baltensperger, U., and Prévôt, A. S. H.: Identification of marine and continental aerosol sources in Paris using high resolution aerosol mass spectrometry, J. Geophys. Res., 118, 1950-1963, doi:1910.1002/jgrd.50151, 2013b.

Freutel, F., Schneider, J., Drewnick, F., von der Weiden-Reinmüller, S.-L., Crippa, M., Prévôt, A. S. H., Baltensperger, U., Poulain, L., Wiedensohler, A., Sciare, J., SardaEstève, R., Burkhart, J. F., Eckhardt, S., Stohl, A., Gros, V., Colomb, A., Michoud, V., Doussin, J. F., Borbon, A., Haeffelin, M., Morille, Y., Beekmann, M., and S., a. B.: Aerosol particle measurements at three stationary sites in the megacity of Paris during summer 2009: Meteorology and air mass origin dominate aerosol particle composition and size distribution, Atmos. Chem. Phys., 13, 933-959, 2013. 